Volume 2 Nomor 1, Maret 2020, Halaman 39 - 45

\title{
Praktek Pemberian MP ASI yang Baik dan Benar di Desa
}

\author{
Balongan \\ Tayong Siti Nurbaeti ${ }^{1}$, Eko Maulana Syaputra ${ }^{2}$ \\ Ilmu Kesehatan Masyarakat Universitas Wiralodra ${ }^{1,2}$ \\ t.siti.nurbaeti@gmail.com ${ }^{1}$,ekomaualanasyaputra@unwir.ac.id
}

\begin{abstract}
Abstrak
Makanan Pendampng ASI (MP-ASI) merupakan makanan atau minuman yang diberikan kepada anak untk memenuhi kebutuhan zat gizi yang didapat selain dari ASI. Hal yang perlu diperhatikan dalam pemberian MP-ASI adalah usia, jenis, frekuensi, porsi dan cara pemberian sesuai dengan tahapan usia anak. Pengabdian kepada masyarakat ini di lakukan di Desa Balongan Kabupaten Indramayu dengan tujuan membantu masyarakat menghasilkan status gizi yang baik. Sasaran kegiatan ini adalah ibu-ibu yang mempunyai baduta di posyandu Desa Balongan diharapkan setelah mengikuti penyuluhan mengenai pemberian MP ASI yang tepat ibu-ibu dapat memberikan MP ASI yang benar untuk anaknya sehingga menghasilkan status gizi yang baik. Hasil dari pengabdian ini yaitu peserta pada saat pre test mempunyai pengetahuan terbanyak pada kelompok pengetahuan cukup sebanyak $66,7 \%$. Setelah dilakukan edukasi dan praktek pembuatan MP ASI mengalami peningkatan pengetahuan yaitu $60 \%$ peserta lebih memahami bagaimana pemberian MP ASI yang baik dan tepat.
\end{abstract}

\section{Kata Kunci : Praktek pemberian MP ASI}

Complementary foods with breast milk (MP-ASI) are foods or drinks that contain nutrients, given to infants or children aged 6-24 months to meet nutritional needs other than breast milk. In giving complementary foods, what needs to be considered are the age of complementary foods, types of complementary foods, frequency of complementary foods, portions of complementary foods, and how to give complementary foods in the early stages. It is hoped that the provision of appropriate complementary foods can not only meet the nutritional needs of babies, but also stimulate feeding skills and stimulate self-confidence in babies. This community service is carried out in Balongan Village, Indramayu Regency with the aim of helping the community produce a good nutritional status. The target of this activity is for mothers who have baduta at the Balongan village posyandu, it is hoped that after attending the counseling on proper complementary breastfeeding, mothers can provide correct MP ASI for their children so as to produce a good nutritional status. The result of this dedication was that participants at the pre-test had the most knowledge in the sufficient knowledge group as much as $66.7 \%$. After education and practice of making complementary breastfeeding, there is an increase in knowledge, namely $60 \%$ of participants understand better how to provide good and appropriate complementary breastfeeding.

Keywords: The practice of giving complementary breastfeeding 


\section{A. Pendahuluan}

Usia 0-24 bulan merupakan masa kritis atau periode golen age dimana pada usia ini pertumbuhan dan perkembangan anak paling optimal. Apabila kabutuhan asupan gizi anak terpenuhi secara optimal maka periode ini dapat terwujud (Soetjiningsih, 1995). Penyebab masalah pertumbuhan anak salah satunya adalah pemberian MP-ASI yang kurang benar dan tidak tepat serta tidak memenuhi kebutuhan gizi yang dibutuhkan sesuai dengan usianya baik secara jenis ataupun jumlahnya.

Makanan Pendamping ASI (MP-ASI) makanan atau minuman terbaik dimana mengandung zat gizi yang diberikan kepada bayi pada usia 6-24 bulan utuk memenuhi kebutuhan gizi yang didapat selain dari ASI. MP-ASI diberikan secara bertahap dalam bentuk makanan padat atau cair sesuai dengan tahapan usia dan kemampuan cerna bayi. (Kemenkes RI, 2014).

Usia, jenis MP-ASI, frekuensi, porsi dan cara pemberian merupakan hal Perlu diperhatikan dalam pemberian MP-ASI kepada anak. Pemberian MP-ASI yang tepat selain dapat memenuhi kebutuhan gizi bayi juga dapat merangsang keterampilan makan dan rasa percaya diri anak (Depkes, 2005). Hal lain yang harus dibperhatikan adalah variasi makanan dan bentuk makanan yang diberikan mulai dari bubur cair, kental, sari buah segar, makanan lumat, makanan lembek, dan sampai makanan padat sesuai dengan usianya (Diah, 2001).

Salah satu faktor penyebab orangtua dalam memberikan makanan pendamping ASI yaitu masih kurangnya pengetahuan yang dimiliki ibu sehingga masih banyak bayi yang mengalami gizi kurang. Oleh karena itu, perlu adanya peningkatan pengetahuan dari para orangtua terkait perilaku dalam memberikan makanan pendamping ASI pada bayinya (Depkes RI,2010).

Masih banyak ibu yang memberikan makanan pendamping ASI secara dini karena kurangnya pengetahuan mengenai pemberian makanan pendamping ASI. Hal ini menyebabkan ibu tidak bisa memilih makanan yang baik untuk diberikan kepada bayinya. Maka dari itu perlu adanya edukasi gizi tentang makanan bergizi dan untuk tenaga kesehatan atau kader posyandu agar selalu memberikan arahan kepada para ibu untuk selalu membawa nakanya ke posyandu untuk mengetahui pertumbuhan dan perkembangan anaknya. Dimana salah satu peran kader posyandu 
adalah memberikan edukasi terkait dari cara memilih makanan sampai cara menyajikan makanan pada anak balita (Wijaya,2010).

Banyak faktor yang mempengaruhi pemberian MP ASI dini oleh ibu. Faktorfaktor tersebut meliputi pendidikan ibu, pengetahuan, petugas kesehatan, budaya dan sosial ekonomi. Berdasarkan latar belakang di atas, maka penulis ingin melakukan pengabdian kepada masyarakat menegenai praktek pemberian MP ASI yang benar di Posyandu Desa Balongan dengan tujuan membantu masyarakat menghasilkan status gizi yang baik..

\section{B. Metode}

Pengabdian kepada masyarakat ini di lakukan di Desa Balongan Kabupaten Indramayu. Sasaran kegiatan ini adalah ibu-ibu yang mempunyai baduta di posyandu Desa Balongan diharapkan setelah mengikuti penyuluhan mengenai pemberian MP ASI yang tepat ibu-ibu dapat memberikan MP ASI yang benar untuk anaknya sehingga menghasilkan status gizi yang baik. Berikut tahapan pelaksanaan pengabdian kepada masyarakat :

a) Persiapan : koordinasi dengan mitra, pembuatan kuesioner pengetahuan MP ASI, penyusunan materi MP-ASI untuk ibu Baduta, MP-ASI pada ibu Baduta oleh kader posyandu, publikasi/undangan dan administrasi.

b) Pelaksanaan : Pre test, Edukasi dasar-dasar MPASI, praktek pembuatan MP ASI dan post test.

c) Evaluasi dan tindak lanjut : Pengisian angket kepuasan pelaksanaan pelatihan.

\section{Hasil dan Pembahasan}

a. Tahap Kegiatan

1. Tahap Persiapan
a. Pengurusan administrasi
b. Persiapan bahan pembuatan MP ASI

2. Tahap Pelaksanaan $\geq$

a. Persiapan : Koordinasi dengan mitra, persiapan alat dan bahan.

b. Pelaksanaan : Pre test, Edukasi dasar-dasar MPASI, praktek pembuatan MP ASI dan post test. 


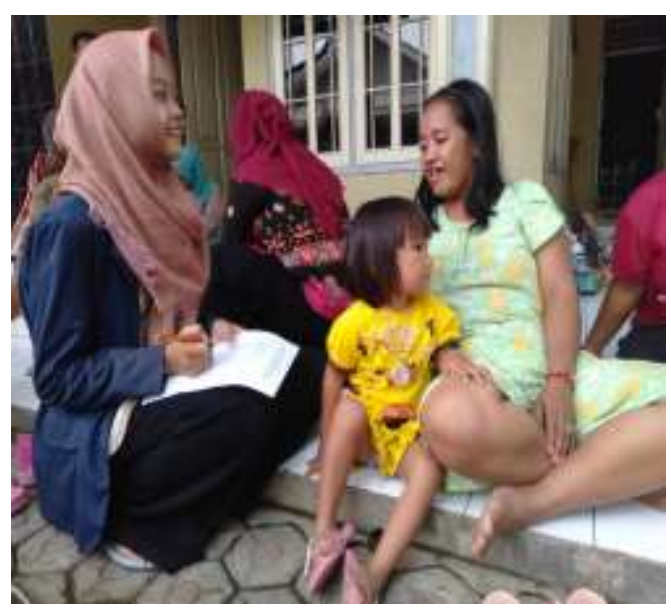

Gambar 1. Pre test

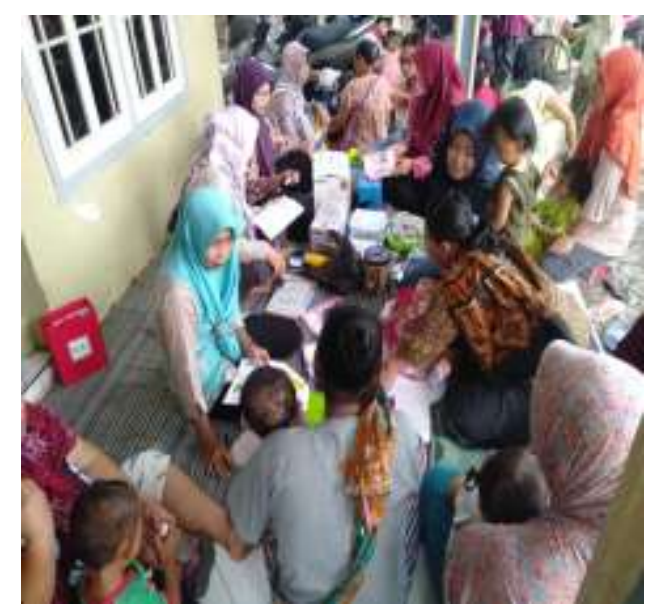

Gambar 2. Post test

Tujuan dari kegiatan pre test dan post test adalah untuk mengetahui pengetahuan ibu-ibu sebelum dan setelah diberikan edukasi mengenai pemberian MP ASI yang baik dan benar. Setelah peserta berkumpul semua, praktek pembuatan MP ASI dimulai. Jumlah peserta dalam penyuluhan dan praktek pembuatan MP ASI sebanyak 15 orang yang terdiri dari 3 kader posyandu dan 12 ibu yang memiliki bayi di usia 6 sampai 24 bulan. Sebelum dilakukan edukasi dan praktek pembuatan MP ASI, terlebih dahulu dilakukan pre test untuk mengetahui pemahaman peserta dalam pemberian MP ASI. Hasil pre tes bisa dilihat pada tabel di bawah ini.

Tabel 5. Distribusi reponden berdasarkan karakteristik responden

\begin{tabular}{lll}
\hline Karakteristik Peserta & $\mathrm{n}(15)$ & $\%$ \\
\hline Umur (Tahun) & & \\
& & \\
\hline$\leq 29$ & 8 & 53,3 \\
\hline$\geq 30$ & 7 & 46,7 \\
\hline Pendidikan & & \\
\hline Sarjana & 3 & 20 \\
\hline SMA & 7 & 46,7 \\
\hline
\end{tabular}


Berdasarkan tabel 5, menunjukkan peserta menurut kelompok umur terbanyak yaitu kelompok umur kurang dari 29 tahun sebanyak 53,3\%. Berdsarkan kelompok pendidikan yang terbanyak yaitu kelompok pendidikan SMA sebanyak 46,7 \%.

Tabel 6. Distribusi peserta berdasarkan pengetahuan saat pre test dan post test

\section{Pre test Post test}

\begin{tabular}{llllllll}
\hline Baik & \multicolumn{3}{c}{ Cukup } & Baik & \multicolumn{3}{c}{ Cukup } \\
& & & & & & & \\
\hline $\mathrm{N}$ & $\%$ & $\mathrm{~N}$ & $\%$ & $\mathrm{n}$ & $\%$ & $\mathrm{n}$ & $\%$ \\
\hline 5 & 33,3 & 10 & 66,7 & 9 & 60 & 6 & 40 \\
\hline
\end{tabular}

Berdasarkan tabel 6 dapat dilihat bahwa peserta pada saat pre test mempunyai pengetahuan terbanyak paa kelompok pengetahuan cukup sebanyak $66,7 \%$. Setelah dilakukan edukasi dan praktek pembuatan MP ASI mengalami peningkatan pengetahuan yaitu $60 \%$ peserta lebih memahami bagaimana pemberian MP ASI yang baik dan tepat.

Dengan adanya kegiatan ini, peserta mengatakan senang karena memperoleh pengetahuan baru tentang berbagai macamMP ASI dan bagaimana cara memberikan MP ASI yang benar dan tepat sesuai dengan usia bayinya. Sebelumnya peserta mengalami kesulitan dalam memberikan variasi MP ASI kepada bayinya.

Kekurangan gizi pada bayi dapat menyebabkan gangguan pertumbuhan dan perekambangan, apabila kondisi ini tidak ditangai sejak dini dapat berdampak pada masa dewasa. Usia 0-24 bulan merupakan masa kritis dimana pertumbuhan dan perkembangan sedang tumbuh dengan sangat cepat atau biasa disebut dengan periode golden age. Periode emas ini bisa terwujud jika bayi dan anak memperoleh asupan gizi yang sesuai dengan kebutuhan untuk tumbuh kembang yang optimal (Zahraini, 2013). Faktor eksternal seperti pola asuh orangtua, asupan gizi, stimulasi dan sosial ekonomi mempunyai pengaruh yang besar terhadap pertumbuhan bayi (Soetjiningsih, 2012). 
Makanan pendamping ASI merupkan makanan dan minuman yang mengandung zat gizi untuk bayi yang harus diberikan kepada bayi yang sudah berusia lenih dari enam bulan agar kebutuhan zat gizi anak terpenuhi selain dari ASI (Notoadmodjo S, 2007). Hal ini dikarenakan pada usia 6-9 bulan ASI hanya mampu memenuhi kebutuhan gizi bayi sebanyak duapertiganya saja dan di usia 912 bulan hanya memenuhi gizi setengah dari kebutuhan bayi (Medise BE, 2011). Pengetahuan MP-ASI yang baik akan mempengaruhi cara pemberian MP-ASI yang baik pula, begitu sebaliknya apabila pengetahuan yang kurang akan mempengaruhi praktek pemberian MPASI yang kurang juga (Yulianti J, 2010). Dismpulkan bahwa pengetahuan MP-ASI sangat mempengaruhi praktek pemberian MP-ASI yang disebabkan oleh tingkat pengetahuan ibu sehingga salah dalam memilih makanan untuk anaknya.

Kesalahan dalam pemilihan dan pengolahan makanan disebabkan karena ketidaktahuan ibu walaupun bahan makanan tersedia (Suharjo, 2009). Selain faktor pengetahuan, dukungan orang terdekat atau atau dukungan keluarga mempunyai pengaruh sehinga akan menghasilkan perilaku ibu dalam pemberian MP ASI. Hasil wawancara dengan ibu-ibu mendapatkan informasi bahwa saran dari keluarga terdekat sulit untuk ditolak, sehingga mereka memberikan MP ASI dini kepada bayinya.

\section{Kesimpulan dan saran}

\section{Simpulan}

Kegiatan praktek pembuatan MP ASI telah diaksanakan dan terdapat peningkatan pengetahuan pada post test setelah dilakukan edukasi mengenai pembrian MP ASI yang benar sebanyak $60 \%$

\section{Saran}

Perlunya pendampingan lebih lanjut dalam praktek pemberian MP ASI dan dilakukan pada semua posyandu terutama di Desa lokus stunting.

\section{Daftar Pustaka}

Departemen kesehatan Republik Indonesia. Manajemen laktasi. Jakarta: 2005.

Depkes RI. Profil Kesehatan Indonesia. Jakarta: Depkes RI. 2010. 
Diah, et al. Menyiapkan makanan pendamping ASI. Jakarta: Puspa Swara; 2001.

Dinkes Provinsi Sumatera Barat. Petunjuk pelaksanaan dan teknis pemberian MPASI Lokal. 2006.

Kemenkes RI. Profil Kesehatan Indonesia . Jakarta. 2014.

Lewis, Sara. Seri PraktisKeluarga Panduan Makanan Pertamaku. Jakarta : Erlangga. 2003.

Medise BE, Sekartini R. Buku pintar bayi. Jakarta: Puspa Swara; 2011

Notoadmodjo S. Kesehatan masyarakat ilmu dan seni. Jakarta: PT Rineka Cipta; 2007.

Soetjiningsih. Tumbuh kembang anak. Jakarta: EGC; 1995

Soetjiningsih. Tumbuh Kembang Anak. Jakarta: Penerbit Buku Kedokteran (EGC); 2012 .

Suhardjo, 2003. Pemberian Makanan Pada Bayi dan Anak.Kanisius. Yogyakarta.

Wijaya, Hendra. Kajian Teknis Standar Nasional Indonesia Biskuit SNI 01-29731992. Balai Besar Industri Argo, Kementrian Perindustrian. 2010.

Yulianti J, 2010. Hubungan Antara Tingkat Pengetahuan Ibu Dan Praktek Pemberian MakananPendamping ASI Dengan Status Gizi Bayi Usia 6 Sampai 12 Bulan

Zahraini Y. 1000 Hari Pertama Kehidupan: Mengubah Hidup , Mengubah Masa Depan Subdit Bina Gizi Makro. 2013 